\title{
AVALIAÇÃO DA EFICIÊNCIA DOS TERMINAIS QUE MOVIMENTAM CONTÊINERES NO BRASIL: UMA ABORDAGEM COMBINADA
}

\section{EVALUATION OF THE EFFICIENCY OF TERMINALS THAT MOVEMENT CONTAINERS IN BRAZIL: A COMBINED APPROACH}

\author{
Renato Leite Fernandes *E-mail: renato.fernandes@marinha.mil.br \\ Marcos Pereira Estellita Lins **E-mail: marcos.estellita.lins@gmail.com \\ Maria Ines Vasconcellos Furtado ${ }^{* * *}$ E-mail: m.ines.vf@gmail.com \\ Helio Rodrigues Valim ${ }^{* *}$ E-mail: eng.valim@infolink.com.br \\ ${ }^{*}$ Centro de Apoio a Sistemas Navais (CASOP), Rio de Janeiro, RJ, Brasil. \\ **Universidade Federal do Rio de Janeiro (COPPE/UFRJ), Rio de Janeiro, RJ, Brasil. \\ ${ }^{* * *}$ Centro Universitário UNILASALLE-RJ, Niterói, RJ, Brasil.
}

\begin{abstract}
Resumo: O transporte marítimo brasileiro possui uma grande importância para o desenvolvimento econômico nacional, quanto mais em um cenário internacional de globalização. Os terminais conteineiros especializados são altamente relevantes nesse contexto, uma vez que representam o principal elo da movimentação de carga por meio de contêineres, os quais normalmente transportam mercadorias de maior valor agregado. Sendo assim, a avaliação da eficiência desses terminais se reveste de grande importância. Alguns trabalhos têm utilizado a Análise Envoltória de Dados (DEA) para medir a eficiência de terminais portuários, em uma abordagem quantitativa. Contudo, as limitações matemáticas dessa modelagem não permitem a utilização de muitas variáveis. Neste caso, a utilização de mapas cognitivos, em uma abordagem qualitativa, permite identificar outras variáveis que sejam relevantes para uma análise mais completa da eficiência. $\mathrm{O}$ objetivo deste trabalho foi articular uma abordagem quantitativa a uma qualitativa, gerando uma abordagem combinada, que pudesse permitir uma análise mais ampla e completa das variáveis relevantes que atuam no setor portuário de movimentação de contêineres, possibilitando um entendimento melhor da eficiência nesse importante setor.
\end{abstract}

Palavras-chave: Terminais de Contêineres. Eficiência. Abordagem Combinada. DEA. Mapas Cognitivos.

Abstract: The maritime transport is of great importance for Brazilians' national economic development, mainly in an international scenario of globalization. Specialized container terminals are highly relevant in this context, since they represent the main link of cargo handling by means of containers, which usually carry goods of higher added value. Therefore, the evaluation of the efficiency of these terminals is of great importance. Despite some papers have been using Data Envelopment Analysis (DEA) to measure the efficiency of port terminals in a quantitative approach, the mathematical limitations of this modelling do not allow the use of many variables. In this case, the use of cognitive maps, in a qualitative approach, allows to identify other variables that are relevant for a more complete analysis of efficiency. The aim of this report is to articulate a quantitative approach to a qualitative one, generating a combined approach that might allow a broader and more complete analysis of the relevant variables that operate in the container handling port sector, enabling a better understanding of efficiency in this important sector.

Keywords: Container Terminals. Efficiency. Combined Approach. DEA. Cognitive Maps. 


\section{INTRODUÇÃO}

O transporte marítimo brasileiro induz o desenvolvimento econômico nacional, ao mesmo tempo em que é resultado da globalização do capital. Além de ser um modal que promove a internacionalização dos mercados (FELIPE JUNIOR, 2016).

Ainda de acordo com a Agência Nacional de Transportes Aquaviários (ANTAQ, 2016), mais de $90 \%$ do comércio internacional passa por instalações portuárias.

Nesse contexto, os terminais conteineiros especializados possuem grande importância no desenvolvimento econômico nacional, uma vez que representam o principal elo da movimentação de carga por meio de contêineres, os quais normalmente transportam mercadorias de maior valor agregado (PANORAMA AQUAVIÁRIO, 2010), impactando de forma relevante a economia do país.

Visando uma avaliação dos principais terminais brasileiros, o presente estudo considerou 19 terminais de contêineres, que movimentaram mais de 100.000 TEU (Twenty-foot Equivalent Unit) em 2008, época em que o cenário nacional e global apresentava elevado crescimento do comércio internacional, movimentando significativamente os terminais de contêineres no Brasil. O Gráfico 1 apresenta os terminais que fizeram parte da amostra.

Gráfico 1 - Movimentação anual de contêineres em 2008

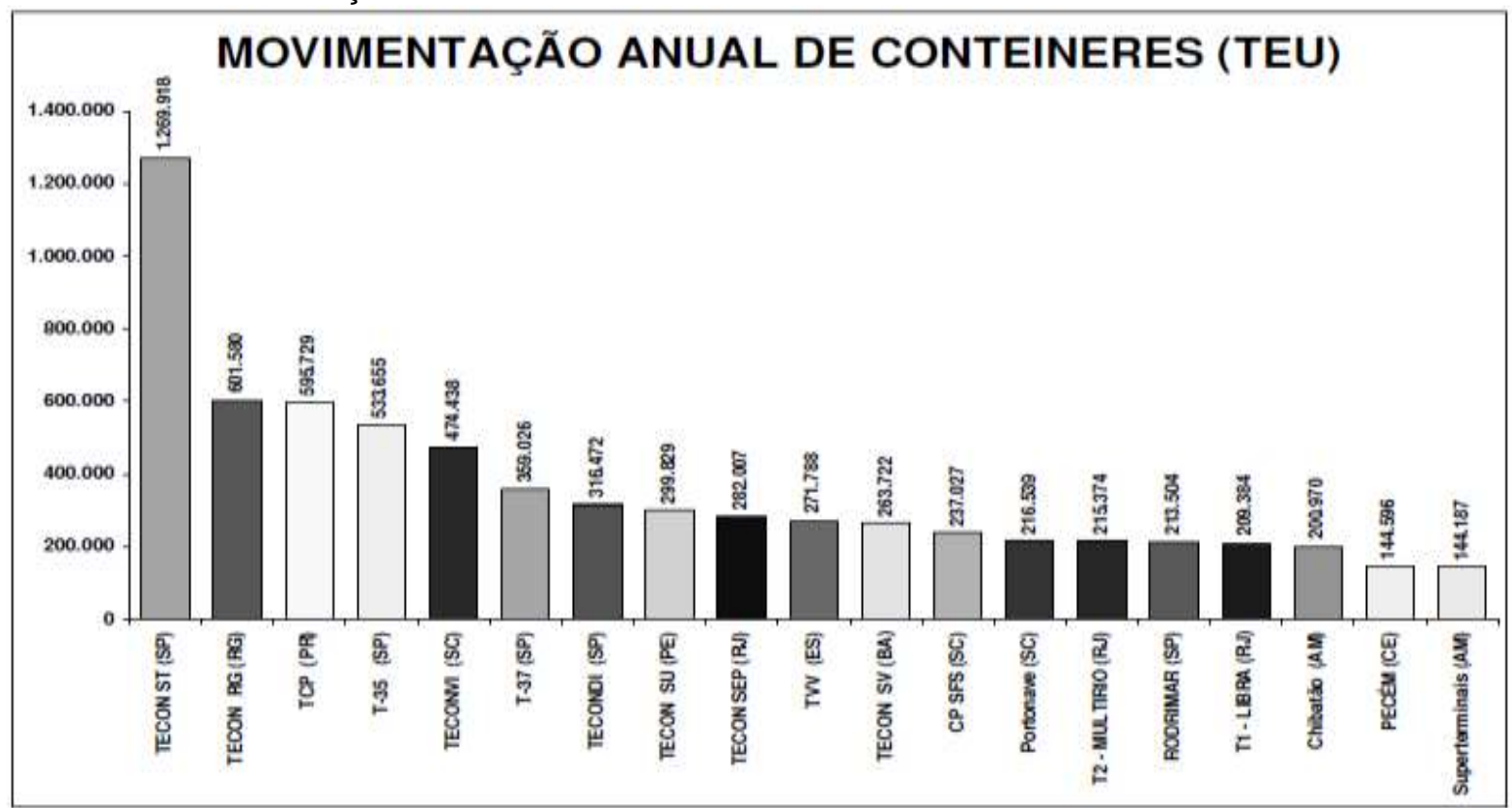

Fonte: Elaborado pelos autores 
As informações sobre os terminais foram obtidas do site da ANTAQ e colhidas junto às administrações portuárias onde se localizam. Essa elevada massa de dados propiciou a utilização de modelos matemáticos, para realizar uma avaliação de abordagem quantitativa em relação à eficiência portuária.

A Análise Envoltória de Dados (DEA - Data Envelopment Analysis), metodologia utilizada para estimar e/ou identificar a fronteira de desempenho eficiente das melhores práticas em indústrias e empresas, foi empregada.

Baseando-se na extensa bibliografia referente à aplicação de DEA na avaliação dos portos, selecionou-se quatro variáveis para compor o modelo matemático, consideradas as mais relevantes e utilizadas, as quais melhor refletiriam a eficiência dos terminais de contêineres.

Devido à complexidade do setor portuário, constatou-se que outras variáveis relevantes também deveriam ser consideradas, pois afetam diretamente a percepção de eficiência dos terminais. Desta forma, buscou-se uma abordagem sistemática para estruturar o problema, identificando outras variáveis importantes, através do uso de mapas cognitivos, em uma abordagem qualitativa.

Sendo assim, o objetivo deste trabalho foi articular uma abordagem quantitativa a uma qualitativa, gerando o que Miguel et al (2012) denomina de abordagem combinada, que pudesse permitir uma análise mais ampla e completa das variáveis relevantes que atuam no setor portuário de movimentação de contêineres, possibilitando um entendimento melhor da eficiência desse importante setor.

\section{METODOLOGIA}

A pesquisa teve caráter aplicado e exploratório, usando em uma abordagem combinada a Análise Envoltória de Dados e Mapas Cognitivos.

\subsection{Análise Envoltória de Dados}

A Análise Envoltória de Dados (DEA - Data Envelopment Analysis) é uma metodologia não-paramétrica, amplamente aplicada na análise de eficiência comparativa entre unidades homogêneas de produção, denominadas Unidades de 
Tomada de Decisão (DMU - Decision Making Units). Isto é, as unidades podem ser analisadas em conjunto, desde que usem as mesmas entradas (inputs) e produzam as mesmas saídas (outputs), com tecnologias similares de produção.

Os modelos clássicos DEA são o CCR, ou de "Retorno Constante de Escala" (CRS - Constant Returns to Scale), desenvolvido por Charnes, Cooper e Rhodes (1978), e o modelo BCC, ou de "Retorno Variável de Escala" (VRS - Variable Returns to Scale), desenvolvido por Banker, Charnes e Cooper (1984). Tais modelos se diferenciam efetivamente pelas fronteiras de eficiência geradas.

De maneira geral, a modelagem DEA objetiva:

a) Determinar a eficiência relativa das DMU, comparando com as demais unidades de produção da amostra;

b) Identificar as origens e o nível de ineficiência relativa das DMU, analisando matematicamente as dimensões atribuídas aos inputs/output;

c) Estabelecer estratégias de produção que maximizem a eficiência técnica das DMU e corrijam as ineficiências existentes, através da geração de alvos a serem atingidos.

O Quadro 1 apresenta os valores das variáveis utilizadas nos modelos DEA CRS e VRS, bem como os respectivos escores de eficiência gerados em tais modelos.

Quadro 1 - Variáveis consideradas e os respectivos escores de eficiência gerados pelos modelos DEA

\begin{tabular}{|c|c|c|c|c|c|c|}
\hline Terminal & $\begin{array}{l}\text { CAIS } \\
\text { (m) }\end{array}$ & $\begin{array}{c}\text { AREA } \\
(\mathrm{m} 2)\end{array}$ & $\begin{array}{c}\text { Equipamentos } \\
\text { (Und) }\end{array}$ & TEU & $\begin{array}{l}\text { Eficiência } \\
\text { CRS }\end{array}$ & $\begin{array}{c}\text { Eficiência } \\
\text { VRS }\end{array}$ \\
\hline TECONVI (SC) & 740 & 180.000 & 23 & 474.438 & 0,9729 & $\mathrm{I}$ \\
\hline TCP (PR) & 564 & 302.800 & 36 & 595.729 & 0,8649 & 0,8685 \\
\hline TECON RG (RG) & 850 & 240.000 & 36 & 601.580 & 0,8637 & $0,904 \mathrm{I}$ \\
\hline TECON SV (BA) & 450 & 73.433 & 19 & 263.722 & 0.9936 & 1 \\
\hline RODRIMAR (SP) & 325 & 70.000 & 17 & 213.504 & 0,8777 & 1 \\
\hline T-35 (SP) & 700 & 250,000 & 28 & 533.655 & 0,8838 & 0,9328 \\
\hline T-37 (SP) & 370 & 130,000 & 18 & 359.026 & 1 & 1 \\
\hline TECON ST (SP) & 980 & 484.000 & 75 & 1.269 .918 & 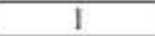 & 1 \\
\hline TECONDI (SP) & 410 & 100.000 & 18 & 316.472 & 1 & 1 \\
\hline CP SFS (SC) & 380 & 86.000 & 14 & 237.027 & 0,9020 & 1 \\
\hline TECON SU (PE) & 660 & 280,000 & 22 & 299.829 & 0,5731 & 0.5941 \\
\hline TVV (ES) & 464 & 108.000 & 17 & 271.788 & 0,8369 & 0,8486 \\
\hline TI - LIBRA (RJ) & 545 & 140,000 & 15 & 209.384 & 0,6220 & 0,6405 \\
\hline T2 - MULTIRIO (RJ) & 533 & 180.000 & 17 & 215.374 & 0,5527 & 0,5571 \\
\hline TECON SEP (RJ) & 540 & 400.000 & 22 & 282.007 & 0,5160 & 0,5408 \\
\hline PECEM (CE) & 350 & 90.000 & 12 & 144.596 & 0,5796 & 1 \\
\hline Superterminais (AM) & 240 & 104,000 & 10 & 144.187 & 0.6463 & 1 \\
\hline Chibatao (AM) & 432 & 125.000 & 25 & 200.970 & 0,5099 & 0.5138 \\
\hline Portonave (SC) & 900 & 270,000 & 15 & 216.539 & 0,5462 & 0,5471 \\
\hline
\end{tabular}

Fonte: Elaborado pelos autores 
Foram consideradas somente as variáveis mais relevantes na literatura sobre o setor, apresentadas no trabalho de Fernandes (2010), a saber: "comprimento do cais", "área do terminal", "quantidade de equipamentos" e "quantidade de carga movimentada".

As variáveis que representam recursos, ou seja, inputs, foram: o comprimento do cais, a quantidade de equipamentos que manipulam diretamente a carga e a área do terminal conteinero. Como output, resultante da operação portuária, foi considerado apenas a quantidade anual de contêineres movimentados, em TEU.

Os escores de eficiência referentes à aplicação dos modelos clássicos às atividades dos terminais nacionais no ano de 2008, orientados a output e apresentando restrição aos pesos virtuais, também são apresentadas no Quadro 1.

$O$ terminal é considerado eficiente se o escore é igual a 1 e ineficiente se menor que 1. Para cada terminal ineficiente, o modelo DEA identifica um conjunto de unidades eficientes que pode ser utilizado como referência, ou seja, benchmarks para melhorar a eficiência do terminal.

\subsection{Mapas Cognitivos}

Segundo Eden (1988), o mapeamento cognitivo pode ser visto como uma tentativa de isolar e representar as idéias de uma pessoa e dispô-las de maneira hierarquizada, obedecendo a lógica de que os resultados/fins/objetivos mais importantes são superiores no mapa. Dessa forma, têm-se no topo dos gráficos, que representam os mapas, os objetivos; no centro, as questões-chave ou estratégicas; e na base, as possíveis ações que sugerem soluções para as questões-chave a que estão ligadas.

O foco principal da utilização de mapas cognitivos no contexto portuário não é resolver o problema, mas sim estruturá-lo.

Há, portanto, dois aspectos interessantes na aplicação dos mapas cognitivos para a avaliação dos terminais:

a) Representar de forma simples e clara os diversos aspectos da problemática que envolve o setor conteinero, sendo possível observar que as variáveis utilizadas no modelo matemático representam somente uma parcela do total de variáveis relevantes; 
b) Criar uma estruturação que possa servir como base para trabalhos futuros visto que, segundo Zawadzki e Belderrain (2008), os métodos que são aplicados na conformação dos problemas procuram viabilizar uma estrutura que possibilite, no futuro, tomadas de decisões em um ambiente já estrategicamente mapeado.

O Quadro 2 apresenta as principais características de um mapeamento cognitivo.

Quadro 2 - Características de um mapa cognitivo

\begin{tabular}{|c|c|c|c|c|}
\hline Objetivo & Obtenção de dados & $\begin{array}{l}\text { Relação } \\
\text { entre } \\
\text { conceitos }\end{array}$ & Formato típico & $\begin{array}{l}\text { Resultado obtido } \\
\text { pela análise }\end{array}$ \\
\hline $\begin{array}{l}\text { Identificar } \\
\text { as relações } \\
\text { de } \\
\text { influência e } \\
\text { causalidad } \\
\text { e entre os } \\
\text { conceitos. }\end{array}$ & $\begin{array}{c}\text { - Entrevista pouco } \\
\text { estruturada, do tipo } \\
\text { Brainstorming, para } \\
\text { identificação dos } \\
\text { Elementos Primários } \\
\text { de Avaliação (EPA) } \\
\text { - Entrevista } \\
\text { estruturada para } \\
\text { identificar os vínculos } \\
\text { causais entre os } \\
\text { conceitos. }\end{array}$ & $\begin{array}{c}\text { - A causa B. } \\
\text { - Porque A é } \\
\text { importante? } \\
\text { - Como } \\
\text { atingir B? }\end{array}$ & $\begin{array}{c}\text { Redes de } \\
\text { associação entre } \\
\text { conceitos com o } \\
\text { uso de setas } \\
\text { indicando o } \\
\text { sentido de } \\
\text { causalidade, } \\
\text { atreladas a sinais } \\
\text { (+ ou -), conforme } \\
\text { a natureza da } \\
\text { relação. }\end{array}$ & $\begin{array}{c}\text { - Redes de } \\
\text { causalidades } \\
\text { construídas para } \\
\text { explicar um evento. } \\
\text { - Sequências de ações } \\
\text { que conduzem a } \\
\text { resultados desejados. } \\
\text { - Lógica que embasa } \\
\text { decisões sobre cursos } \\
\text { alternativos de ação } \\
\text { para atingir metas } \\
\text { desejadas. }\end{array}$ \\
\hline
\end{tabular}

Fonte: Zawadzki e Belderrain (2008)

Buscando-se gerar um mapeamento das percepções qualitativas do problema, foram utilizados mapas cognitivos do tipo causal, os quais são centrados no raciocínio causal que liga entidades ao longo do tempo, ou no raciocínio que embasa decisões.

Baseado nessas características, e utilizando a metodologia desenvolvida por Rosenhead e Mingers (2001), os mapas cognitivos foram elaborados de acordo com a seguinte seqüência de construção:

1. Definição do rótulo do problema;

2. Identificação dos Elementos Primários de Avaliação (EPA);

3. Construção e hierarquização dos conceitos.

Foram entrevistados quatro agentes com expressivo conhecimento no setor conteineiro: o presidente de uma das maiores transportadoras mundiais especializada em contêineres, um executivo de um moderno terminal de contêineres 
brasileiro, um professor especialista em infraestrutura portuária e o Diretor de Portos da agência reguladora federal.

A fim de conduzir todo o processo de elaboração do mapa, extraíram-se dos entrevistados suas perspectivas acerca dos problemas relacionados à eficiência dos terminais, e deu-se forma ao mapa, abordando aspectos subjetivos do pensamento de cada agente.

Diferentemente da macroestrutura hierárquica básica preconizada na literatura, na qual os conceitos são interligados pelos arcos direcionais seguindo a ordem: Opções $\rightarrow$ Questões-Chave $\rightarrow$ Objetivos (RIEG; ARAÚJO FILHO, 2003), a construção dos mapas do setor conteineiro seguiu a ordem inversa, partindo dos objetivos representados pelos Elementos Primários de Avaliação (EPA) até as opções. Essa macroestrutura mostrou-se mais organizada e de melhor compreensão do que aquela, para o desenvolvimento deste trabalho.

Sendo assim, a partir do rótulo do problema foi realizado um brainstorming com cada entrevistado, e também foi utilizado um conjunto de perguntas que serviu para identificar os EPA, os quais formaram a base para a construção dos mapas. Os entrevistados geraram diferentes "conceitos cabeça", ou seja, idéias que, por sua vez, geraram implicações e originaram ligações de influência, representando os objetivos a serem atingidos.

Buscou-se estabelecer diversos elementos primários de avaliação, pois, de acordo com Zawadzki e Belderrain (2008), uma característica dos mapas que possuem pequena quantidade de EPA é a pobreza de informações, que pode comprometer a definição do problema.

Os conceitos foram construídos com frases curtas que forneceram um aspecto de ação ao pensamento dos entrevistados.Os primeiros conceitos geraram a pergunta: "Como fazer para atingir este conceito?"

Esta pergunta foi efetuada repetidas vezes gerando novos conceitos "conceitos meio". Quando a pergunta alcançava um nível de detalhamento que fugia ao objetivo do trabalho, consideravam-se as respostas esgotadas, gerando assim os "conceitos cauda", isto é, constructos que representavam opções para se encerrar um caminho que emanava dos diferentes EPA.

Visando dar dinamismo e simplicidade aos mapas, tendo em vista a complexidade da problemática portuária e o alto nível de conhecimento dos agentes 
entrevistados em relação ao setor de movimentação de contêineres, não foram feitas perguntas do tipo "Por que este conceito é importante?", pois se pressupôs que todos os conceitos abordados seriam importantes, a priori.

Os constructos foram interligados por ligações de influência, repetindo este processo para todos os conceitos originados de um EPA, gerando um arranjo organizado do mapa cognitivo.

\subsection{Abordagem Combinada}

Sendo DEA uma ferramenta de abordagem quantitativa, e o mapeamento cognitivo essencialmente qualitativo, propôs-se que os resultados DEA fossem analisados considerando-se as diversas variáveis relacionadas com a problemática da eficiência portuária, estruturadas pelos mapas cognitivos. Buscou-se, então, articular as duas metodologias apresentadas, utilizando uma abordagem combinada.

Dessa forma, os resultados do modelo matemático representado por DEA receberiam subsídios das informações fornecidas pelos mapas cognitivos, permitindo validar os resultados quantitativos e analisar outras variáveis relacionadas com a eficiência oriundas da percepção dos especialistas portuários.

Ressalta-se que as variáveis identificadas pelos especialistas expressam apenas os pontos de vista daqueles que estão envolvidos diretamente no processo, e que certamente outros fatores e variáveis podem ser identificados por outros profissionais portuários.

Visto que os resultados DEA já foram apresentados no início deste artigo, o próximo tópico abordará somente a aplicação dos mapas cognitivos na identificação das demais variáveis relevantes oriundas da estruturação do problema.

\section{APLICAÇÃO DOS MAPAS COGNITIVOS}

\subsection{Construção dos Mapas Cognitivos}

A percepção do grupo entrevistado permitiu contemplar diferentes e complementares percepções do problema, representativas das mais importantes 
organizações envolvidas, possibilitando modelar adequadamente a complexidade do sistema através da elaboração de quatro mapas cognitivos individuais distintos.

Para todos os entrevistados o rótulo do problema foi apresentado como: "AUMENTAR A EFICIÊNCIA DOS TERMINAIS DE CONTÊINERES".

Os EPA foram gerados a partir do rótulo do problema, originando constructos que foram expondo o "como fazer", até se alcançar os "conceitos cauda".

O uso dos mapas cognitivos para estruturar o problema relacionado à eficiência dos terminais permitiu que os entrevistados apresentassem seus pontos de vista. Posteriormente, estes tiveram a oportunidade de observar o mesmo problema sob a ótica dos outros entrevistados.

Essa ferramenta permitiu a identificação de diversos fatores relevantes para o problema da eficiência portuária, ainda mais quando se considera que há diferentes interesses em jogo e que grupos heterogêneos de decisores podem ter visões e objetivos complementares ou conflitantes.

\subsection{Mapa Agregado}

Os quatro mapas individuais reunidos formaram um mapa agregado, o qual foi utilizado para unir e relacionar entre si as idéias expostas nos mapas individuais. Dessa forma, conseguiu-se consolidar e representar em um mapa único as perspectivas de indivíduos diferentes que, neste caso, acabaram expondo muitas idéias similares. Logo, foi criada uma estrutura de relacionamento entre esses conceitos, os quais foram unidos por meio de ligações de influência, gerando um mapa com forte caráter de complementaridade de idéias.

De acordo com a literatura relacionada com avaliação portuária, e observando-se que de fato há uma forte relação entre terminais considerados eficientes e aqueles que mais aumentam sua movimentação, foi estabelecido como "conceito cabeça": "AUMENTAR A QUANTIDADE DE CONTÊINERES MOVIMENTADOS".

O mapa agregado foi decomposto em três mapas representando seus três grandes eixos: transporte e acesso ao terminal, movimentação dentro do terminal e transporte marítimo. Segue uma breve análise dos eixos do mapa agregado. 


\subsubsection{Eixo do Transporte e Acesso ao Terminal}

A figura 1 representa o eixo do transporte e acesso ao terminal, que agregou os conceitos relacionados com o transporte da carga até o terminal, sendo focada a infraestrutura externa do terminal.

Figura 1 - Eixo do Transporte e Acesso ao Terminal

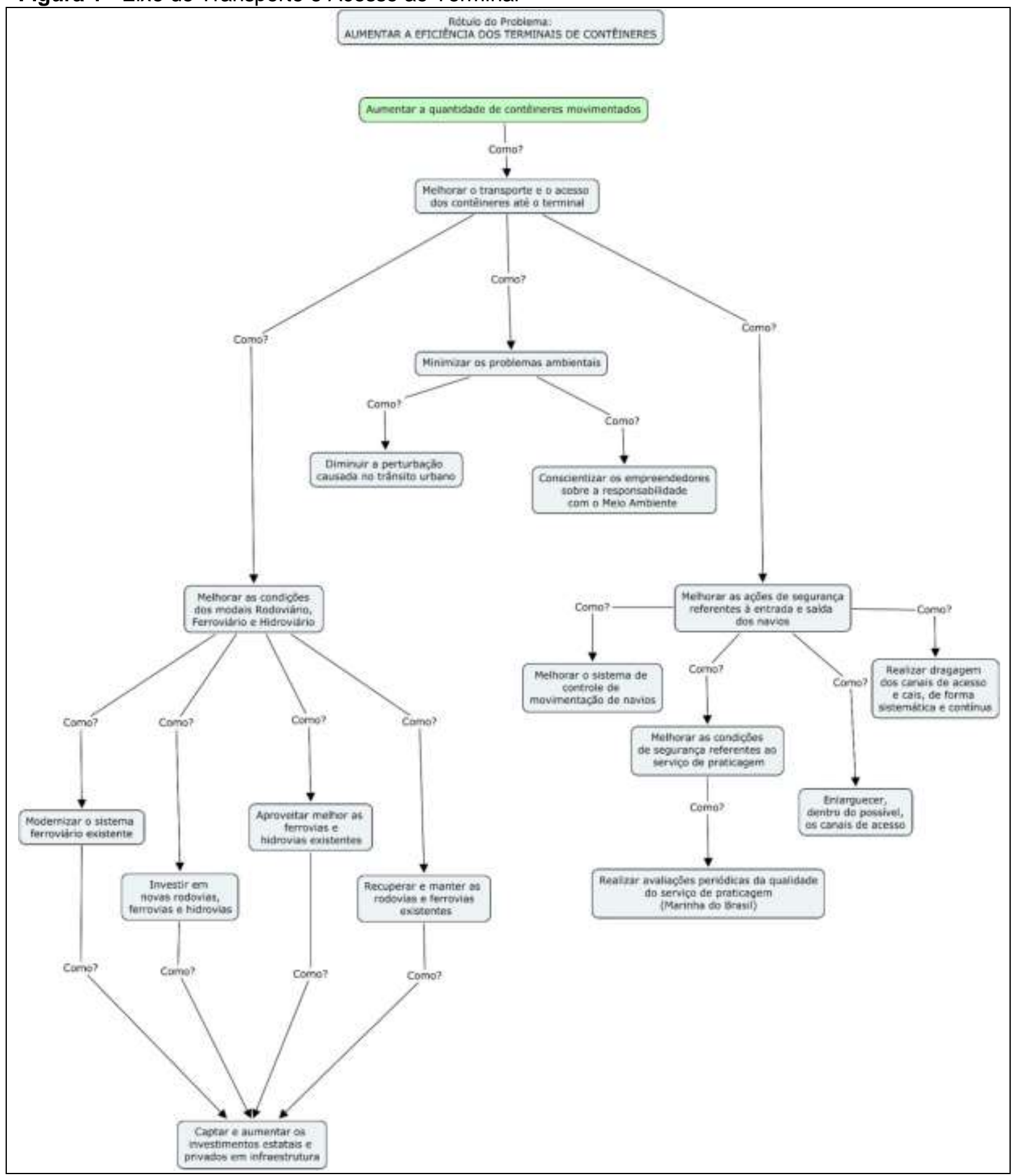

Fonte: Elaborado pelos autores

Revista Produção Online. Florianópolis, SC, v.17, n. 3, p. 1045-1068, 2017. 
Por meio desse eixo do mapa é possível observar que uma das formas de melhorar o fluxo de carga até o terminal residiria na minimização dos problemas ambientais. Isso estaria relacionado com a diminuição do impacto do trânsito urbano no transporte de carga, e vice-versa. Uma tendência mundial para o estabelecimento de novos terminais tem se baseado na instalação desses em áreas mais afastadas dos grandes centros urbanos, buscando a utilização de uma malha de transportes adequada e não saturada.

Igualmente, a conscientização dos empreendedores em relação ao meio ambiente também afetaria o transporte e acesso de contêineres. Isso porque, caso os projetos de construção ou ampliação de terminais não cumprissem todas as exigências estabelecidas pelos organismos estatais de regulamentação ambiental, seria gerada inevitavelmente uma demora do licenciamento ambiental, e, por conseguinte, um atraso na execução e conclusão das obras necessárias à expansão e ampliação da capacidade de movimentação de contêineres.

Esse eixo do mapa agregado também mostra que, ao se tratar da questão da movimentação de contêineres fora da área do terminal, há de se considerar a importância das ações de segurança relacionadas à entrada e saída de navios do porto. Para que haja uma melhoria nesse aspecto, a qual influenciaria positivamente o transporte e acesso de contêineres, seria necessário dragar e alargar os canais de acesso ao terminal, visando evitar a ocorrência de acidentes que possam colocar em risco vidas humanas e a navegabilidade do canal.

Ao se melhorar as condições de largura e profundidade do canal, além do aspecto de segurança, haveria uma influência direta na possibilidade de aumento de fluxo de carga, pois um canal mais profundo e mais largo possibilitaria o acesso de navios de maior capacidade a fim de operarem no terminal, gerando uma provável economia de escala.

Para alguns terminais, o grande fluxo de navios apresenta um significativo aumento do risco de acidentes nos períodos de pico de operação, quando uma grande quantidade de embarcações navega conjuntamente no canal. Logo, a melhoria da sistemática de controle de acesso de navios, em conjunto com o incremento das condições de segurança dos serviços de praticagem, poderia corroborar para um efetivo aumento da segurança da navegação e, por conseguinte, para a melhoria da condição de acesso da carga até o terminal. 


\subsubsection{Eixo da Movimentação Dentro do Terminal}

A carga conteinerizada apresenta dois fluxos distintos de movimentação: um fora do terminal e o outro dentro do terminal. $O$ eixo que expressa essa movimentação intraterminal, representado pela figura 2, agregou constructos que são relacionados com a operação da carga no interior do terminal.

Figura 2 - Eixo da Movimentação Dentro do Terminal

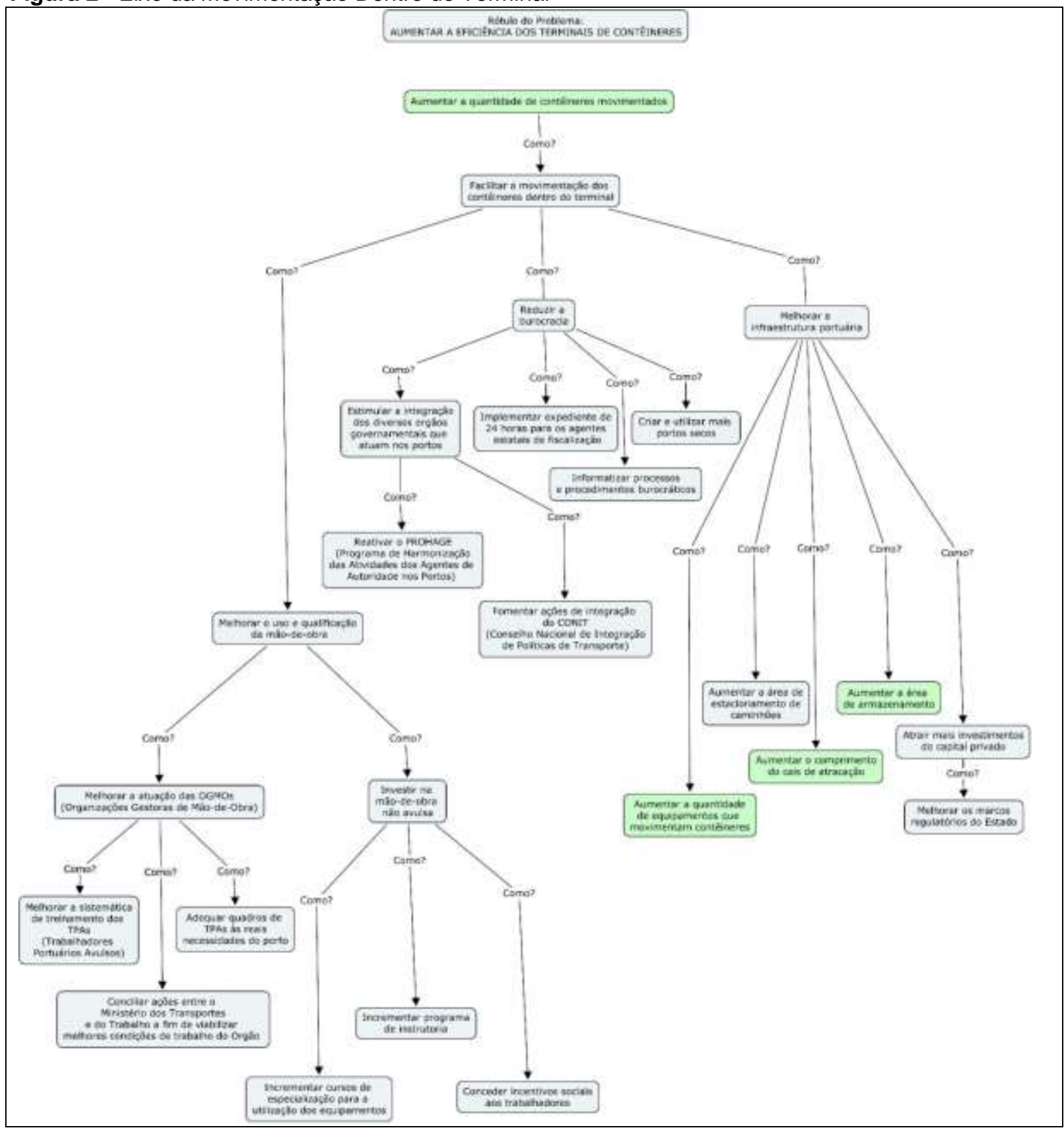

Fonte: Elaborado pelos autores 
De acordo com o eixo observado, a fim de se implementar uma melhor dinâmica dos contêineres dentro dos terminais, seriam necessárias ações baseadas na melhoria do uso e da qualificação da mão-de-obra (avulsa e não avulsa), bem como medidas para se reduzir a burocracia e para se melhorar a infraestrutura portuária.

Para melhorar a qualidade da mão-de-obra, seria necessária uma atuação mais efetiva dos Órgãos Gestores de Mão de Obra (OGMOs). Para se dinamizar a atuação dos OGMOs, seria necessário um maior respaldo jurídico às suas ações, viabilizado por um melhor entendimento entre o Ministério dos Transportes e os demais órgãos do poder executivo e do judiciário relacionados com as atividades trabalhistas.

Assim como com os Trabalhadores Portuários Avulsos (TPAs), o investimento na qualificação dos demais trabalhadores portuários também seria uma medida desejável, visando facilitar o fluxo de carga no terminal. A oferta de cursos e a instituição de programas planejados de instrução elevariam o nível profissional do pessoal, que certamente desempenharia um trabalho de qualidade superior. Igualmente, a concessão de incentivos sociais como, por exemplo, plano de saúde, vale-refeição, vale transporte, etc. possivelmente elevariam o comprometimento e motivação dos trabalhadores.

Ainda segundo esse eixo do mapa, a redução da burocracia seria um aspecto essencial dentro desse eixo. A integração sempre foi um desafio para a administração pública, mas essa tarefa seria de grande importância para dinamizar o fluxo de carga no terminal.

De certa forma os terminais parecem se ressentir da atuação direta dos agentes estatais de fiscalização, tanto em relação ao expediente de trabalho como em relação aos processos burocráticos de liberação de carga.

Portos Secos são recintos alfandegados de uso público, situados normalmente em áreas adjacentes às regiões produtoras e consumidoras, nos quais são executadas operações de movimentação, armazenagem e despacho aduaneiro de carga. A utilização mais ampla e a criação desse tipo de estrutura seriam medidas eficazes no sentido de agilizar a movimentação dos contêineres para os mercados consumidores, visto que a prestação dos serviços aduaneiros em porto 
seco próximo ao domicílio dos agentes econômicos envolvidos proporciona uma grande simplificação de procedimentos burocráticos.

Observando-se o aspecto físico das operações com a carga, a infraestrutura portuária é o elemento que mais impacta a movimentação dos contêineres dentro de um terminal. Basicamente todos os entrevistados expuseram a importância de uma adequação/aumento da quantidade de equipamentos que efetivamente movimentam contêineres, bem como um aumento/adequação da área de armazenamento e comprimento do cais.

Equipamentos, cais e área seriam elementos fundamentais para o fluxo da carga do navio para o terminal e do terminal para o navio, sendo que a melhoria das condições de uso desses elementos certamente representaria um aumento da capacidade de movimentação de contêineres.

Aqui é possível verificar as três variáveis de input que são utilizadas no modelo de Análise Envoltória de Dados.

Uma vez que o modal rodoviário é o mais utilizado para o transporte de contêineres no Brasil (HIJJAR, 2006), o aumento da área de estacionamento de caminhões nos terminais também representaria uma importante medida para melhorar o fluxo de carga, evitando o retardamento da entrega e do recebimento de contêineres no terminal.

Por fim, segundo os constructos desse eixo, a melhoria da infraestrutura do terminal seria implementada na medida em que o capital privado investisse mais nos terminais. Obviamente, a segurança para que esses investimentos gerassem retorno para os investidores dependeria de uma melhoria do marco regulatório imposto pelo governo, que garantiria uma continuidade das regras em vigor.

\subsubsection{Eixo do Transporte Marítimo}

O terceiro eixo, representado pela figura 3, agregou conceitos relacionados com o incremento do transporte marítimo que se daria pelo aumento da quantidade de rotas marítimas e freqüência de atracação dos navios nos portos. 
Figura 3 - Eixo do Transporte Marítimo

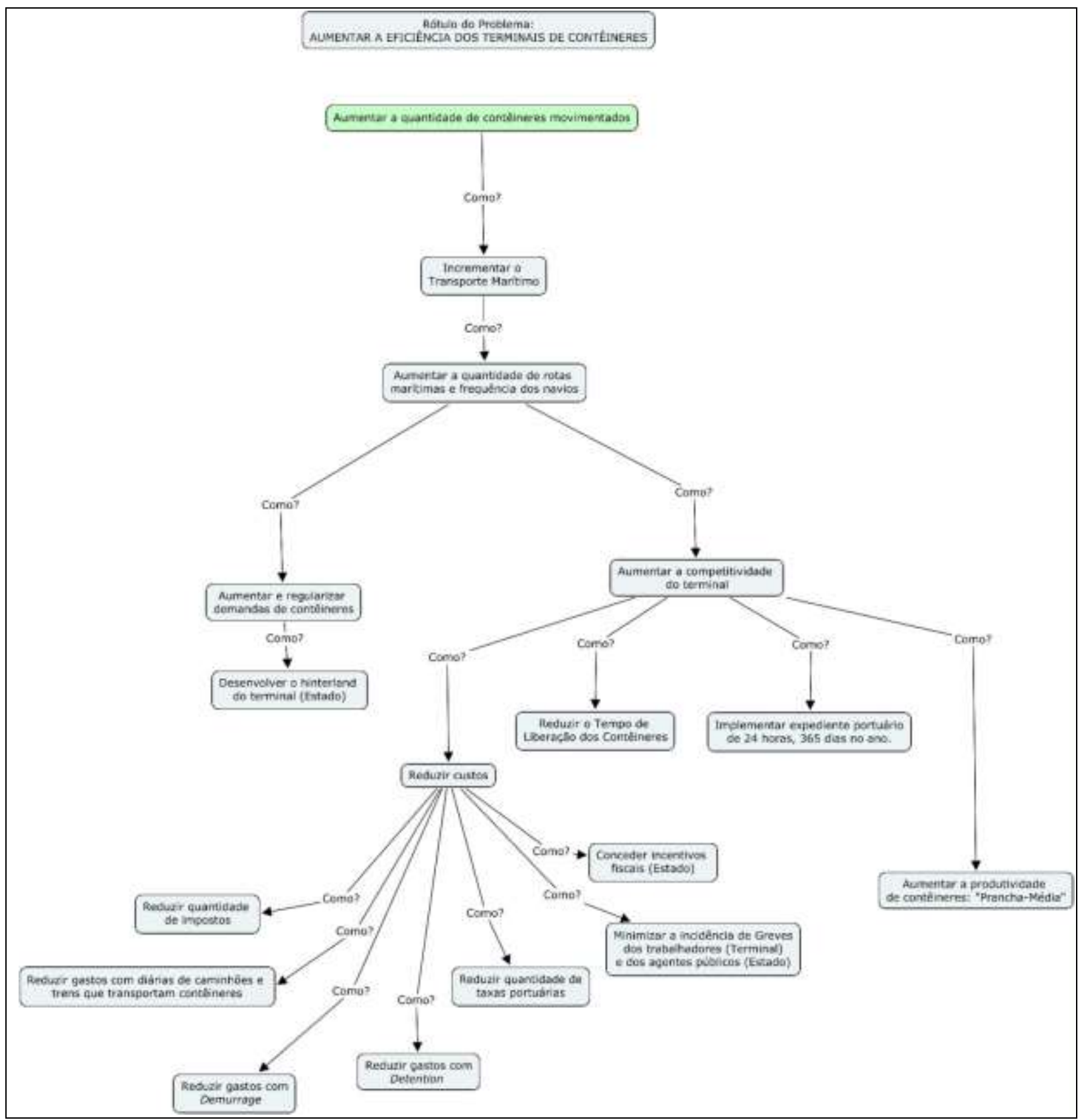

Fonte: Elaborado pelos autores

De acordo com o armador entrevistado, esse incremento é função direta do fator econômico, ou seja, está baseado na redução dos custos e no aumento dos lucros advindos da comercialização da carga.

Segundo a análise desse eixo, o aumento e regularização das demandas de contêineres representariam um aumento direto do fluxo de navios no terminal. Essa maior demanda de carga seria função das características do mercado consumidor associado a esse terminal, ou seja, seu hinterland. Desta forma, mercados consumidores economicamente fortes gerariam demandas mais elevadas de 
mercadorias. Logo, seria necessária a implementação de políticas por parte do estado a fim de incentivar o desenvolvimento econômico das regiões que abrigam os terminais.

As ações visando o aumento da competitividade do terminal foram apontadas pelos entrevistados como um elemento de grande importância para trazer mais navios e consecutivamente mais carga para os terminais. A redução dos custos com o transporte dos contêineres está na base da atratividade de carga.

O eixo ainda aponta que seria necessária uma redução da quantidade de taxas e impostos que incidem sobre a carga, bem como a diminuição de gastos relacionados com o transporte dos contêineres até o terminal, e os relacionados com sobreestadia (demurrage e detention), que normalmente ocorrem em função da burocracia que imprime morosidade ao processo.

Dois conceitos importantes que foram incorporados a partir do mapa individual do terminal dizem respeito à concessão de incentivos fiscais por parte do estado e minimização da incidência de greves nos terminais. Os incentivos seriam um atrativo de carga na medida em que houvesse uma redução dos impostos para a operação com carga conteinerizada, e a minimização de greves, tanto dos agentes públicos quanto dos trabalhadores portuários, garantiria a estabilidade do fluxo de contêineres, não dando margem a prejuízos decorrentes dessas paralisações.

Outra informação que esse eixo do mapa mostra é que a implementação do expediente de 24 horas por dia, o ano inteiro, representaria um aumento de competitividade visto que se ofereceria aos armadores a possibilidade de operarem a qualquer hora do dia, em qualquer dia do ano, flexibilizando a estadia dos navios no terminal.

Por fim, o aumento da produtividade, ou seja, da prancha-média que é a quantidade de contêineres movimentados do cais para o navio e do navio para o cais em uma hora, seria um elemento que aumentaria a competitividade do terminal. Contudo, vale ressaltar que essa velocidade de carga e descarga estaria diretamente ligada à necessidade de se movimentar os contêineres com maior celeridade. Similarmente ao conceito de "velocidade econômica" de um veículo, existe uma forte relação entre o aumento da velocidade de movimentação de carga e a elevação dos custos associados a esse aumento. Dependendo da demanda do terminal, não é interessante economicamente alocar mais mão-de-obra e 
equipamentos para atender rapidamente um navio e após isso ter as operações de movimentação paradas até a chegada de outra embarcação.

\section{RESULTADOS}

Modelos quantitativos DEA exprimem os resultados obtidos para uma avaliação de eficiência, baseando-se nas relações matemáticas das variáveis utilizadas, reportando a eficiência técnica que é um conceito ligado estritamente à relação nível de insumos e nível de produtos.

Sendo esse um modelo matemático que perde poder de discriminação com a diminuição da relação entre o número de DMU e o de variáveis, buscou-se contornar o problema restringindo o número de variáveis. Conforme descrito anteriormente, foram consideradas somente as seguintes variáveis: "comprimento do cais", "área do terminal", "quantidade de equipamentos" e "quantidade de carga movimentada".

A elaboração dos mapas cognitivos expôs a complexidade do problema e permitiu avaliar modelo DEA em relação à validação dos seus resultados. Os Mapas apresentaram outras variáveis que não deveriam ser omitidas da análise de desempenho se o objetivo é ter uma percepção mais ampla da avaliação de eficiência dos terminais.

Diferentemente do trabalho de Mingers, Liu e Meng (2009) que, na abordagem combinada, utilizaram mapas cognitivos para descobrir as variáveis mais importantes, escolhendo assim os inputs e outputs para a modelagem em DEA, neste trabalho os resultados do modelo matemático foram comparados com as informações fornecidas pelos mapas cognitivos, permitindo verificar se os resultados quantitativos, levando-se em consideração a identificação de diversas variáveis que refletem a realidade da percepção dos especialistas portuários.

\subsection{Variáveis oriundas do mapa agregado}

O Quadro 3 foi elaborado segundo a subdivisão dos três eixos oriundos do mapa agregado, transformando os constructos em variáveis por meio da substantivação das ações/idéias. 
Quadro 3 - Variáveis oriundas do mapa agregado

\begin{tabular}{|c|c|}
\hline \multicolumn{2}{|l|}{ 1- Eixo do Transporte e Acesso ao Terminal } \\
\hline Variáveis & Classificaçào \\
\hline \multicolumn{2}{|l|}{ 1.1 - Condiçôes dos modais rodoviário, ferroviário e hidroviário } \\
\hline 1.1.1 - Modernização do sistema ferroviário existente & DM \\
\hline 1.1.2 - Investimentos em novas rodovias, ferrovias e hidrovias & MD \\
\hline 1.1.3 - Nível de aproveitamento das rodovias, ferrovias e hidrovias existentes & DM \\
\hline 1.1.4 - Nível de recuperação das rodovias e ferrovias existentes & DM \\
\hline 1.1.5 - Captaçăo de investimentos estatais/privados & MD \\
\hline \multicolumn{2}{|l|}{ 1.2 - Problemas ambientais } \\
\hline 1.2.1 - Perturbação no trânsito urbano & DM \\
\hline 1.2.2 - Nível de consciência dos empreendedores com o Meio Ambiente & NM \\
\hline \multicolumn{2}{|l|}{ 1.3 - Segurança em relação à entrada e saída dos navios do porto } \\
\hline 1.3.1 - Controle da movimentaçăo de navios & DM \\
\hline 1.3.2 - Nível de qualidade do serviço de praticagem & DM \\
\hline 1.3.3 - Largura do canal de acesso & MA \\
\hline 1.3.4 - Profundidade do canal de acesso & MA \\
\hline \multicolumn{2}{|l|}{ 2. Eixo da Movimentaçào Dentro do Terminal } \\
\hline Variáveis & Classificaçào \\
\hline \multicolumn{2}{|l|}{2.1 - Nível de Burocracia } \\
\hline 2.1.1 - Integração dos diversos orgðos governamentais que atuam no porto & NM \\
\hline 2.1.2 - Expediente dos agentes de fiscalizaçăo & MA \\
\hline 2.1.3 - Nível de informatização dos processos e procedimentos burocráticos & DM \\
\hline 2.1.4 - Utilização de Portos Secos & MD \\
\hline \multicolumn{2}{|l|}{ 2.2- Uso e qualificaçào da mào-de-obra } \\
\hline \multicolumn{2}{|l|}{ 2.2.1 - Nível de atuação das OGMOs } \\
\hline 2.2.1.1 - Treinamento dos TPAs & DM \\
\hline 2.2.1.2 - Adequaçăo dos quadros de TPAs às necessidades do terminal & MD \\
\hline $\begin{array}{l}\text { 2.2.1.3 - Nível de relacionamento do Ministério dos Transportes com a Justiça do } \\
\text { Trabalho para melhorar atuaçao das OGMOs }\end{array}$ & NM \\
\hline \multicolumn{2}{|l|}{ 2.2.2 - Mào-de-obra não avulsa } \\
\hline 2.2.2.1 - Nível de especialização para utilizaçăo de equipamentos & DM \\
\hline 2.2.2.2 - Nível do programa de instrutoria para todos os trabalhadores & DM \\
\hline 2.2.2.3 - Incentivos sociais aos trabalhadores & MD \\
\hline \multicolumn{2}{|l|}{2.3 - Infraestrutura portuária } \\
\hline 2.3.1 - Área de estacionamento de caminhøes & MA \\
\hline 2.3.2 - Quantitativo de equipamentos que efetivamente movimentam contêineres & MA \\
\hline 2.3.3 - Comprimento do cais de atracação & MA \\
\hline 2.3.4 - Área do terminal (armazenamento) & MA \\
\hline 2.3.5 - Nível de investimentos do capital privado (marco regulatório estável) & MD \\
\hline \multicolumn{2}{|l|}{ 3- Eixo do Transporte Marítimo } \\
\hline Variáveis & Classificaçào \\
\hline \multirow{2}{*}{\multicolumn{2}{|c|}{$\begin{array}{l}\text { 3.1 - Quantidade de rotas marítimas e frequência dos navios } \\
\text { 3.1.1 - Demanda de contêineres }\end{array}$}} \\
\hline & \\
\hline 3.1.1.1 - Nível de desenvolvimento do hinterland do terminal & DM \\
\hline \multicolumn{2}{|l|}{ 3.1.2 - Competitividade do terminal } \\
\hline 3.1.2.1 - Custos para operaçăo no terminal & \\
\hline 3.1.2.1.1 - Quantidade/valor de impostos incidentes & MD \\
\hline 3.1.2.1.2 - Gastos com diárias de caminhøes e trens & MD \\
\hline 3.1.2.1.3 - Gastos com Demurrage & MD \\
\hline 3.1.2.1.4 - Gastos com Detention & MD \\
\hline 3.1.2.1.5 - Quantidade/valor de taxas incidentes & MD \\
\hline $\begin{array}{l}\text { 3.1.2.1.6 - Tempo de paralisaç̧o do terminal por conta de greves } \\
\text { (trabaihadores e agentes estatais) }\end{array}$ & MD \\
\hline 3.1.2.1.7 - Nível de incentivos fiscais & MD \\
\hline 3.1.2.2 - Tempo de liberação de contêineres & MD \\
\hline 3.1.2.3 - Expediente portuário & MA \\
\hline 3.1.2.4 - Produtividade de movimentaçấo de contêneres (prancha-média) & MA \\
\hline
\end{tabular}

Fonte: Próprios autores

De acordo com o acesso aos dados, as variáveis foram classificadas como "mensuráveis com acesso aos dados" (MA), "mensuráveis com difícil acesso aos dados" (MD), "difícil mensuração" (DM) e "não-mensuráveis" (NM). 
Foram identificadas 37 variáveis, das quais algumas são aglutinações de constructos, como por exemplo, "condições de segurança referentes ao serviço de praticagem" e "avaliações periódicas da qualidade dos serviços de praticagem". Como o segundo constructo fornece uma opção de como se alcançar o primeiro, ambos foram aglutinados para melhor estruturação do problema, gerando então a variável "nível de qualidade do serviço de praticagem".

Desse total de variáveis, nove foram consideradas mensuráveis com acesso aos dados (MA), como largura e profundidade do canal marítimo, que foram facilmente verificadas junto à Marinha do Brasil por intermédio da Diretoria de Hidrografia e Navegação (DHN), e as que tratam da infraestrutura portuária propriamente dita como, por exemplo, o quantitativo de equipamentos e 0 comprimento do cais atracável, que puderam ser consultados junto à ANTAQ.

Outras 14 variáveis se apresentaram como mensuráveis, mas com difícil acesso aos dados (MD), por alguns motivos dos quais se ressalta o sigilo em torno de informações que exprimem investimentos de recursos financeiros, como o nível de investimento de capital privado e os custos para operação do terminal. Também são de difícil acesso os dados relacionados com variáveis de mão-de-obra, como quadro adequado de Trabalhadores Portuários Avulsos (TPA) e quantitativo de incentivos sociais dados aos trabalhadores.

Onze variáveis foram consideradas de difícil mensuração (DM), pois apresentam elementos que se mostram de difícil quantificação como, por exemplo, o nível de treinamento e especialização dos trabalhadores portuários e o nível de informatização dos processos e procedimentos burocráticos.

Três variáveis se apresentaram com elevado nível de subjetividade, sendo consideradas não-mensuráveis (NM). São elas o nível de consciência dos empreendedores com o meio ambiente, a integração dos diversos órgãos governamentais que atuam no porto e o nível de relacionamento do Ministério dos Transportes com o Ministério do Trabalho e a Justiça do Trabalho, a fim de melhorar a atuação das Organizações Gestoras de Mão-de-obra (OGMO).

Ressalta-se que a essas 37 variáveis soma-se a variável "quantidade de contêineres movimentados em um ano", que foi gerada a partir do "conceito cabeça" atribuído aos três eixos do mapa agregado. Assim sendo, observa-se que o modelo DEA, ao utilizar quatro variáveis, utiliza pouco mais de $10 \%$ das variáveis que, 
segundo os especialistas do setor portuário, deveriam ser consideradas em uma análise mais completa da eficiência dos terminais.

\subsection{A eficiência dos terminais}

Conforme exposto, o modelo DEA gera escores de eficiência técnica, todavia, abordando um conceito mais amplo da eficiência, e considerando a opinião dos entrevistados, um terminal eficiente é aquele que cumpre seus objetivos, utilizando da melhor maneira possível seus recursos a fim de atender de forma barata, segura, simples, organizada e rápida o escoamento da carga conteineirizada, minimizando a permanência do navio no porto e da carga nas áreas de armazenagem.

Analisando-se os resultados dos escores de eficiência gerados pelo modelo matemático à luz dos conceitos expostos no mapa cognitivo agregado, de forma a conciliar os resultados do modelo DEA às variáveis observadas no mapa agregado, é possível chegar a conclusões que auxiliem uma melhor compreensão do nível de eficiência de cada terminal.

A infraestrutura do terminal é um elemento de grande importância na avaliação da eficiência, entretanto, possuir uma boa e organizada área de armazenagem, um cais de comprimento adequado e utilizar equipamentos modernos e em quantidade adequada para movimentar contêineres pode não ser o suficiente a fim de que um terminal seja considerado eficiente. Por exemplo, se houver dificuldades para que os contêineres e os navios cheguem e saiam do porto, todo o fluxo de carga será impactado, e possivelmente a percepção de eficiência também será afetada. 
Quadro 4 - Situação dos principais portos brasileiros (2008)

\begin{tabular}{|c|c|c|c|c|c|c|c|}
\hline \multirow[t]{2}{*}{ Porto } & \multicolumn{2}{|c|}{ Acesso } & \multicolumn{2}{|c|}{$\begin{array}{l}\text { Calado Operacional } \\
\text { Máximo }(\mathrm{m})(1)\end{array}$} & \multirow{2}{*}{$\begin{array}{l}\text { Espera } \\
\text { Média para } \\
\text { Atracação }\end{array}$} & \multirow{2}{*}{$\begin{array}{l}\text { Produtividade } \\
\text { Média }\end{array}$} & \multirow[t]{2}{*}{ Retroárea } \\
\hline & Aquaviário & Terrestre & Atual & Necessário & & & \\
\hline Pecém & Excelente & Excelente & 13,5 & 14 & 4 & 31 & Adequada \\
\hline Suape & Excelente & Excelente & 14 & 14 & 4 & 29 & Adequada \\
\hline Salvador & Satisfatório & Satisfatório & 12 & 12,5 & 9 & 34 & Crítica \\
\hline Vitória & Insatisfatório & Insatisfatório & 9,3 & 12,5 & 9 & 39 & Insuficiente \\
\hline Rio & Satisfatório & Insatisfatório & 12,3 & 13,5 & 6 & 31 & Adequada \\
\hline Itaguaí & Insatisfatório & Insatisfatório & 14,3 & 14,3 & 9 & 39 & Adequada \\
\hline Santos & Insatisfatório & Crítico & 11,8 & 13,5 & 13 & 39 & Crítica \\
\hline Paranaguá & Crítico & Insatisfatório & 10,3 & 12,5 & 11 & 31 & Adequada \\
\hline $\begin{array}{l}\text { São Francisco } \\
\text { do Sul }\end{array}$ & Insatisfatório & Insatisfatório & 9,5 & 12,5 & 14 & 35 & Crítica \\
\hline Itajaí & Insatisfatório & Insatisfatório & 9,5 & 11,5 & 20 & 23 & Crítica \\
\hline Rio Grande & Excelente & Excelente & 12,2 & 12,5 & 7 & 41 & Insuficiente \\
\hline
\end{tabular}

Fonte: CMA CGM - Relatório para a Comissão de Serviços e Infraestrutura do Senado Federal 2008

O Quadro 4 apresenta a situação dos principais portos brasileiros no ano de 2008 em relação ao acesso, profundidade, espera para atracação, produtividade e retro área. Observa-se que essas variáveis constam no mapa agregado.

Os acessos à maioria dos portos, onde os terminais conteineiros estão localizados, apresentavam dificuldades em 2008. Por exemplo, o acesso aquaviário ao Porto de Santos era insatisfatório em virtude do grande volume diário de navios nos canais de acesso ao porto, criando uma pressão de movimentação muito grande, implicando em atrasos para a atracação e, de certa forma, em uma degradação das condições de segurança da navegabilidade no canal.

Por outro lado, portos mais novos e bem planejados possuem normalmente uma excelente disponibilidade de acesso terrestre e aquaviário. É o caso do Porto de Suape, construído na década de 90, nas proximidades da cidade de Recife-PE, e que possui um excelente acesso aquaviário e uma boa malha viária para o atendimento da movimentação da carga.

Como se pode observar, o Porto de Santos possui dificuldades de acesso e problemas relacionados com o atendimento a navios de maior porte, porém, de acordo com a modelagem matemática, todos os terminais desse porto foram considerados eficientes. Por outro lado, o TECON SUAPE, que está localizado no Porto de Suape, apresentou um baixo escore de eficiência, porém o acesso terrestre e aquaviário ao porto, bem como a profundidade do canal figuram entre as melhores do Brasil. 
Sendo assim, mostra-se relevante analisar os resultados DEA, terminal por terminal, utilizando o conjunto de variáveis oriundas do mapa agregado.

\section{CONSIDERAÇÕES}

O estudo exposto neste trabalho reforça os argumentos de que a modelagem DEA, ao fornecer um índice de eficiência baseado em uma abordagem essencialmente quantitativa, mesmo utilizando as variáveis consideradas como as mais importantes para o setor de transporte de contêineres, apresenta um resultado parcial e incompleto.

A abordagem qualitativa, representada pelos mapas cognitivos gerados por meio de entrevistas com alguns dos principais atores do setor conteinero, possibilitaram a identificação de conceitos objetivos e subjetivos que geraram variáveis significativas, as quais poderiam ser consideradas em uma análise focada na percepção global de eficiência portuária.

Por intermédio do mapa agregado foram identificadas 38 variáveis que representam elementos importantes para a avaliação de desempenho dos terminais conteineiros. A maior parte dessas variáveis é mensurável, e as informações podem ser colhidas de acordo com a disponibilidade de acesso a elas.

Dessa forma, a utilização de DEA, sendo articulada e subsidiada com informações oriundas dos mapas cognitivos, em uma abordagem combinada, permitiu uma análise mais ampla e completa das variáveis relevantes que atuam no setor portuário de movimentação de contêineres, possibilitando um entendimento melhor da eficiência desse setor.

Embora os dados da pesquisa sejam de 2008, a metodologia de articulação das abordagens quantitativa e qualitativa mostrou-se adequada para um melhor entendimento do problema, podendo ser empregada na avaliação da eficiência de terminais de contêineres em qualquer período de tempo.

De acordo com o que foi apresentado neste trabalho, mostra-se plausível a utilização desse tipo de abordagem combinada na avaliação de eficiência de outros sistemas produtivos, propiciando, assim, futuros projetos de pesquisa. 


\section{REFERÊNCIAS}

ANTAQ - Agência Nacional de Transportes Aquaviários. Brasília, 2017. Disponível em: <http://www.antaq.gov.br>. Acesso em: 04 fev.2017.

BANKER, R. D.; CHARNES, A.; COOPER, W. W. Some models for estimating technical and scale inefficiencies in data envelopment analysis. Management Science, v. 30, n. 9, p.1078-1092, 1984. http://dx.doi.org/10.1287/mnsc.30.9.1078.

CARLINI, N. CMA CGM. Relatório para a Comissão de Serviços e Infraestrutura do Senado Federal. 2009. Disponível em:

<http://www.senado.gov.br/sf/comissoes/ci/ap/AP_20081204_NelsonCarlini.pdf> Acesso em: 10 jun. 2011.

CHARNES, A.; COOPER, W. W.; RHODES, E. Measuring the efficiency of decision making units. European Journal of Operational Research, n.2, pp.429-444, 1978.

http://dx.doi.org/10.1016/0377-2217(78)90138-8

EDEN, C., Cognitive mapping: a review. EJOR, v. 36, pp. 1-13, 1988.

http://dx.doi.org/10.1016/0377-2217(88)90002-1

FERNANDES, R.L., 2010, Avaliação dos terminais que movimentam contêineres no brasil através da análise envoltória de dados. Dissertação (Mestrado) - COPPE/UFRJ, Rio de Janeiro, RJ.

FELIPE JUNIOR, N.F. O setor portuário e marítimo brasileiro: avanços e limitações. Revista Geofronter, 2015. Disponível em: <

https://periodicosonline.uems.br/index.php/GEOF/article/download/819/nelson > Acesso em: 29 abr. 2016

HIJJAR, M. F.; ALEXIM, F. M. B, 2006. Avaliação do acesso aos terminais portuários e ferroviários de contêineres no Brasil. Coppead/UFRJ, Centro de Estudos em Logística. Disponível em:

<http://www.ilos.com.br/site/index.php?option=com_content\&task=view\&id=702\&ltemid=74>. Acesso em: 20 dez. 2009.

MIGUEL, P. A. C. (Organizador). Metodologia de pesquisa em engenharia de produção e gestão de operações. 2 ed. Rio de Janeiro: Elsevier, 2012.

MINGERS, J.; LIU, W.; MENG, W., 2009, Using SSM to Structure the Identification of Inputs and Outputs in DEA. Journal of Operational Research Society, n.60, pp.168-179. http://dx.doi.org/10.1057/palgrave.jors.2602542

PANORAMA AQUAVIÁRIO. Brasília: Agência Nacional de Transportes Aquaviários ANTAQ, v.5, 2010. Disponível em: <http://www.antaq.gov.br> Acesso em: 13 out. 2015.

RIEG, D. L.; ARAÚJO FILHO, T. Mapas cognitivos como ferramenta de estruturação e resolução de problemas: o caso da Pró-reitoria de extensão da UFSCar. Gestão \& Produção, v.10, n.2, pp. 145-162, 2003. Disponível em:<http://www.scielo.br/pdf/gp/v10n2/a03v/0n2.pdf >. Acesso em: 30 jan. 2014. 
ROSENHEAD, J.; MINGERS, J., 2001, Rational analysis for a problematic world: problem structuring methods for complexity, uncertainty and conflict. 2. ed. West Sussex: John Willey \& Sons. http://dx.doi.org/10.1002/sres.491

ZAWADZKI, M.; BELDERRAIN, M. C. N. O uso de mapas cognitivos para a estruturação de problemas. In: SIGE 2008 - SIMPÓSIO DE APLICAÇÔES EM ÁREAS DE DEFESA, 10., 2008. Anais... São José dos Campos, 2008.

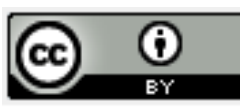

Artigo recebido em 02/03/2017 e aceito para publicação em 18/04/2017

DOI: http://dx.doi.org/10.14488/1676-1901.v17i3.2761 